\title{
Preparación de Membranas para Producción de Agua Potable
}

\author{
Rosa M. Ribeiro, Rosângela Bergamasco, Marcelino L. Gimenes y Carmen M. O. Müller \\ Universidade Estadual de Maringá, Departamento de Engenharia Química, \\ Bloco D-90, Avenida Colombo N 5790, CEP 87020-900 Maringá, PR-Brasil. \\ (e-mail: rosamr@deq.uem.br)
}

\begin{abstract}
Resumen
En este trabajo se presenta un estudio sobre la síntesis de membranas poliméricas asimétricas para la producción de agua potable. La filtración usando membranas es un proceso alternativo para el tratamiento de aguas, donde la membrana actúa como una barrera selectiva que bloquea el pasaje de algunos componentes. En este trabajo algunas muestras de agua fueron infectadas con $10^{7}$ a $10^{8}$ unidades formadoras de colonias (UFC) por $\mathrm{ml}$ con la bacteria Escherichia coli. El proceso utilizado fue la inversión de fases y las membranas fueron preparadas a partir de soluciones poliméricas, con polisulfona y con fluoruro de polivinilideno. En ambos casos, se agregó poli metacrilato de metilo a las soluciones poliméricas, usando $\mathrm{N}, \mathrm{N}$-dimetilformamida como solvente. Algunas membranas removieron entre 99 y $100 \%$ de las colonias bacterianas, con un flujo de $300 \mathrm{~L} / \mathrm{h} \mathrm{m}^{2}$.
\end{abstract}

Palabras claves: escherichia coli , síntesis de membranas, filtración, agua potable

\section{Preparation of Membranes for the Production of Drinking Water}

\begin{abstract}
This paper describes the synthesis of asymmetric polymer membranes used for the production of drinking water. Filtration of water through the membranes is an alternative method for water treatment, where the membrane acts as a selective barrier which blocks the passage of some components. Water samples for this study were inoculated with $10^{7}$ to $10^{8}$ colony forming units (CFU) of Escherichia coli per $\mathrm{ml}$. The process used was phase inversion, and the membranes were prepared beginning with polymer solutions, including polysulfone and polyvinylidene fluoride. In both cases polymethyl methacrylate was added to the polymeric solutions, using $\mathrm{N}, \mathrm{N}$-dimethylformamide as solvent. Some of the membranes prepared achieved bacterial removal of 99 to $100 \%$, at a flow of $300 \mathrm{~L} / \mathrm{h} \mathrm{m}^{2}$.
\end{abstract}

Keywords: escherichia coli , membrane synthesis, filtration, drinking water 


\section{INTRODUCCIÓN}

Brasil, es un país de dimensiones continentales, con grandes reservas acuíferas que corresponden al $16 \%$ de las reservas de agua dulce del planeta. En territorio brasileño se encuentra parte del acuífero Guaraní, que constituye una de las mayores reservas de agua dulce subterránea del mundo. Es un bien que debe ser preservado, pues la disponibilidad de agua en el mundo para uso directo está escaseando día pos día, debido a varios factores que han degradado diversos cuerpos hídricos, tales como: explosión demográfica, derribada de árboles próximo a las nacientes, polución proveniente de desagües industriales y domésticos entre otros (ABES, 2000). La Comisión Mundial para el Agua en siglo XXI, un grupo formado con el apoyo de la ONU y del Banco Mundial, alerta que hasta año 2025 la necesidad de agua será $17 \%$ mayor que el total disponible en la actualidad. Si cambios no son hechos, la demanda será $56 \%$ superior a la capacidad actual. Estos cambios envuelven el respeto al medio ambiente, el uso racional de aguas y el tratamiento adecuado de las mismas.

El Decreto Estadual 12.486 20/10/78, Portaría 1469 de 29/12/2000, FUNASA Fundación Nacional de Salud, define agua potable como siendo aquella propia para el consumo humano, cuyos parámetros microbiológicos, físicos, químicos y radiactivos atiendan el padrón de potabilidad y que no ofrezcan riesgos a la salud. Debe seguir los parámetros de calidad, expuestos en la Tabla 1.

Tabla 1: Parámetros para agua potable. La especificación es para $90 \%$ de las muestras

\begin{tabular}{|l|l|}
\hline Parámetros & Especificación \\
\hline $\begin{array}{l}\text { E coli o } \\
\text { Termotolerantes }\end{array}$ & Ausencia en $100 \mathrm{ml}$ \\
\hline Coliformes totales & Ausencia en $100 \mathrm{ml}$ \\
\hline Turbiedad & $\begin{array}{l}1,0 \text { UT (unidad de } \\
\text { turbiedad }\end{array}$ \\
\hline
\end{tabular}

La tecnología usual de tratamiento de aguas contaminadas envuelve, de forma general, la coagulación con sales de hierro o aluminio, sedimentación, filtración y desinfección con cloruro. La combinación de estos tratamientos tiene como objetivo la remoción de organis- mos patogénicos, como se ha demostrado en la literatura (Schneider y Tsutiya, 2001). Desde los años 60, cuando las membranas de acetato de celulosa fueron desarrolladas, se descubrió su potencial de uso para el tratamiento de aguas naturales y residuales (Nóbrega et al, 1997). Estas membranas están presentes en todos los sistemas biológicos, desempeñando las más variadas funciones. Las membranas sintéticas surgieron con la intención de imitar las membranas naturales, siendo necesario observar y comprender el fenómeno de la permeación además de desenvolver técnicas de síntesis de las mismas (Nóbrega et al., 1997).

La filtración por medio de membranas es un proceso donde ésta desempeña el papel de una barrera selectiva que restringe el pasaje de determinados compuestos tales como: iones, compuestos orgánicos, etc.

Los Procesos con Membranas han sido utilizados en los más variados sectores, desde la industria química, en la quiebra de azeótropos de mezclas de solventes orgánicos, hasta la área médica, como en la hemodiálisis y en la dosificación controlada de remedios, pasando por la biotecnología, industria alimenticia, farmacéutica y en el tratamiento de aguas industriales y municipales.

Las membranas son clasificadas de acuerdo con el tamaño de los poros: Osmosis Reversa:< 0,002 $\mu \mathrm{m}$; Nanofiltración: < 0,002 $\mu \mathrm{m}$; Ultra filtración: 0,2-0,02 $\mu \mathrm{m}$ y Micro filtración: 4-0,2 $\mu \mathrm{m}$. Los sistemas de micro filtración y ultra filtración son empleados para la remoción de material particulado y coloidal de aguas brutas. La osmosis reversa es utilizada para a desalinización de aguas. Los procesos de separación por membranas presentan una serie de ventajas. Entre ellas, se pueden destacar: ahorro energético, selectividad y simplicidad de operación. Estas características permiten que membranas puedan competir con las técnicas clásicas de separación (Nóbrega et al., 1997). Como desven-tajas, las membranas presentan: elevados costos, tazas de flujo pequeñas y tiempo de vida útil limitado. Con el objetivo de disminuir estas desventajas, nuevos materiales y nuevas técnicas de síntesis de membranas están siendo investigadas. 
En este trabajo, se estudió el uso de membranas para el tratamiento de aguas contaminadas $\mathrm{y}$, por medio de algunas soluciones poliméricas, fueron preparadas diferentes membranas asimétricas, estudiadas específicamente para el tratamiento de aguas contaminadas con la bacteria Escherichia coli (E.coli).

\section{MATERIAL Y MÉTODOS}

\section{Preparación de las Membranas}

La técnica de inversión de fase (Ribeiro, 2005) fue utilizada en la preparación de las membranas seguido de la coagulación de la solución polimérica por medio de precipitación por inmersión, como se describe a continuación. Como soporte de las membranas se usaron láminas de poliéster-polipropileno.

Las membranas fueron hechas a partir de una solución polimérica (polímero + solvente + sal), la cual fue esparcida formando una fina película sobre el soporte, que se apoyaba sobre una placa de vidrio $(17 \times 25 \mathrm{~cm})$. Dos hilos de nylon de $\varnothing 0,35 \mathrm{~mm}$ mantenían el soporte fijo a los bordes de la placa de vidrio. El diámetro de los hilos determinó el espesor de las membranas obtenidas. Posteriormente la película de solución fue sumergida en baño de agua durante 4 horas a $20^{\circ} \mathrm{C}$ (Petrus, 1997). Durante la inmersión el no-solvente (agua) es absorbido por la solución polimérica, dando paso a una separación de fases en toda la longitud de la lámina de solución / película formando, de esta manera, la estructura y porosidad de la membrana. Varias concentraciones de polímeros (Fluoruro de Polivinilideno-PVDF e Polisulfona), Polimetacrilato de metilo, sal (Cloruro de Potasio) y solvente (N,N-Dimetilformamida) fueron usadas obteniéndose, de esta forma, membranas diferentes.

\section{Procedimiento Microbiológico}

Siguiendo la metodología adaptada de Milles, (1938) para la realización del conteo de la $E$. coli fueron preparadas soluciones de caldo nutritivo de soja (TSB) al $0,8 \%$ y soluciones salinas al $0,85 \%$, ambas en agua destilada. Se toma un volumen de solución TSB y se adiciona $2 \%$ de Agar-Agar (solidificante); la solución TSB pasa a denominarse TSA y posteriormente es calentada para promover su fusión. Estas tres soluciones (TSB, salinas e
TSA) fueron auto clavadas a $127^{\circ} \mathrm{C}$, por 15 minutos para la esterilización de las mismas. En las placas de Petri fue vertida solución y fueron colocadas en la estufa a $36^{\circ} \mathrm{C}$ por 24 horas. Procedimiento - A partir de la cultura padrón de $E$ coli, se inoculó una placa con la solución TSA, con una alzada de la cultura padrón. Posteriormente a la incubación de la cultura a $37^{0} \mathrm{C}$ por 24 horas, fueron preparados los inóculos en TSB con carga bacteriana de aproximadamente $1-5 \times 10^{8} \mathrm{UFC} / \mathrm{ml}$ por comparación con la turbación de lo tubo $\mathrm{n}^{0} 5$ de la escala McFarland. El inóculo preparado fue utilizado para contaminar un volumen de agua desionizada, obteniéndose una carga bacteriana de aproximadamente $10^{6}-10^{7}$ UFC. Esta agua contaminada por la bacteria fue filtrada en la membrana previamente preparada. Se dejó un volumen de esta agua contaminada sin pasar por la membrana para utilizar como control de conteo de bacterias. La muestra fue filtrada a través de la membrana y fue en seguida diluida en soluciones salinas de $10^{-1}, 10^{-2}, 10^{-3 \mathrm{~h}}$ a $10^{-4}$ y el control, de $10^{-1}$ a $10^{-5}$.

Las diluciones de las muestras y del control fueron sembradas en 4 cuadrantes de placa utilizándose la técnica de gota $(20 \mu \mathrm{l})$ e incubadas por 24 horas a $37^{\circ} \mathrm{C}$. El conteo fue realizado en el cuadrante donde el número de colonias estaba entre 30 y 60 .

El porcentaje de remoción se calculó por medio de la siguiente ecuación:

$\mathrm{R} \%=\{1-[$ UFC-F $) /($ UFC-C) $]\} \times 100$

En la ecn. (1), UFC-F significa filtrado y UFCC significa contaminado.

\section{Evaluación de las Membranas}

La Figura 1 muestra el módulo usado para experimentar las membranas preparadas $\mathrm{El}$ módulo tiene una capacidad de 0,31 L; altura de $11 \mathrm{~cm}$ y su área de filtración es de 10,5 $\mathrm{cm}^{2}$.

Las membranas preparadas se evaluaron de acuerdo a su capacidad de eliminación de la bacteria E. coli y de su capacidad para mantener un flujo elevado. Se utilizó un módulo "dead-end" cilíndrico de acero inoxidable, en cuyo interior había una chapa metálica perforada para soporte de las membranas 
estudiadas. Durante los ensayos se mantuvo agitación magnética para evitar la formación de depósitos sobre las membranas.

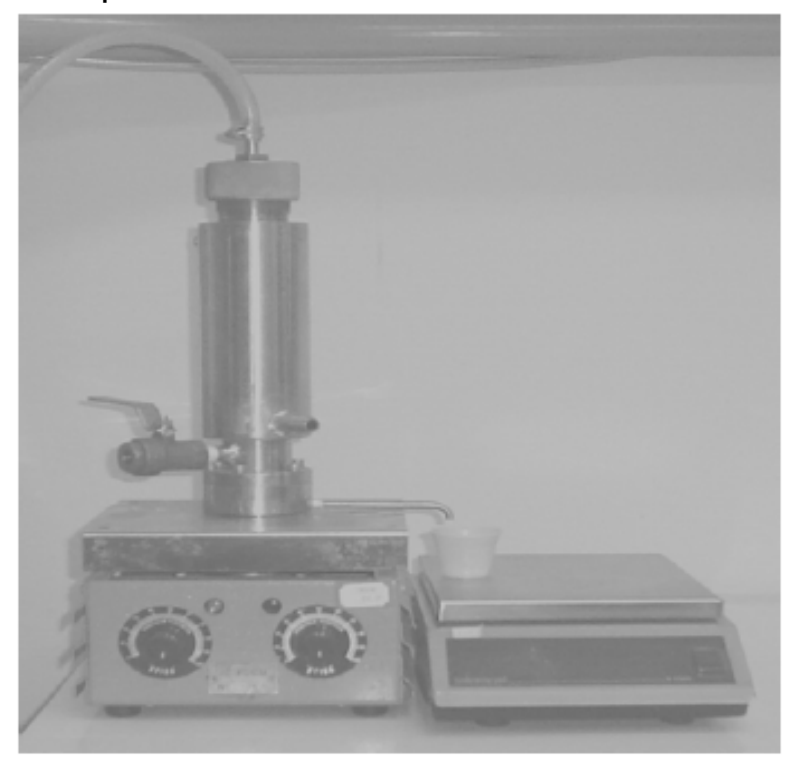

Fig.1: Módulo de filtración "Dead End"

El flujo filtrado se obtuvo por caudal volumétrico a una presión de operación de $3 \mathrm{~atm}$ (Ultra filtración) y se determinó de acuerdo a los procedimientos adoptados por el Standard Methods (APHA, 1995). Los ensayos con las membranas fueron realizados intercaladamente haciendo lavados con soluciones de $\mathrm{NaOH} 0,5 \%(\mathrm{v} / \mathrm{v})$, de $\mathrm{HNO}_{3} 0,5 \%(\mathrm{v} / \mathrm{v})$ y con agua. Finalmente fueron enjuagadas con agua destilada, para su posterior reutilización. La asepsia de estas membranas fue hecha con alcohol al $70 \%$.

\section{Caracterización de membranas preparadas}

Esta caracterización fue realizada por medio de Microscopía Electrónica (se seleccionó la mejor membrana) y por métodos analíticos para todas las membranas.

\section{a) Capacidad de retención de las Membranas}

El nivel de retención de las membranas se determinó por ultra filtración de albúmina de suero bovino (BSA), con un peso molecular de 67.000 Daltons, de acuerdo a la siguiente ecuación:

$R(\%)=\left[I-C_{p} / C_{c}\right] \cdot 100$

Aquí:

$\mathrm{C}_{\mathrm{p}}=$ Concentración de BSA del filtrado
$\mathrm{C}_{\mathrm{c}}=$ Concentración de BSA del concentrado $\mathrm{R} \%=$ porcentaje retenido

La determinación de la concentración de las muestras de filtrado y concentrado se hizo por espectrofotometría a $280 \mathrm{~nm}$, con espectrofotómetro Shimadzu UV-1203.

b) Radios aparentes promedios de los poros

Los radios promedios de los poros de las membranas se determinaron de acuerdo con la ecuación 2 (Ribeiro, 2005), donde se utilizan los resultados obtenidos en la ecuación 2:

$R=100 \cdot(a / r)$

En esta ecuación:

$\mathrm{R}=$ porcentaje de retención del soluto BSA

$a=$ radio medio del soluto $\left(40 \mathrm{~A}^{0}\right)$

$r=$ radio medio de los poros de la membrana

En el presente estudio se utilizó agua que fue contaminada con una carga bacteriana elevada de la bacteria $E$ coli. La tabla 2 muestra los parámetros que caracterizan el agua utilizada en este trabajo.

\section{Caracterización del agua}

El agua en estudio fue caracterizada cada vez que era contaminada. En la tabla 2 se presenta la media de estas caracterizaciones.

Tabla 2: Caracterización del agua en estudio

\begin{tabular}{|l|l|}
\hline \multicolumn{2}{|l|}{ Agua contaminada con E coli } \\
\hline Carga bacteriana & $10^{7}-10^{8}$ UFC \\
\hline $\mathrm{pH}$ & 6,1 \\
\hline Color & 18 \\
\hline Turbidez & 37 \\
\hline
\end{tabular}

\section{RESULTADOS Y DISCUSIÓN}

La primera etapa de este trabajo consistió en un estudio experimental utilizando una planificación experimental factorial. Para éste se determinaron los factores (reactivos) y los respectivos niveles (concentraciones) que serían utilizados en la preparación de las soluciones poliméricas. Se decidió trabajar en dos niveles de concentraciones, mínimo (-) y máximo $(+)$, con dos polímeros Fluoruro de 
Polivinilideno - PVDF y Polisulfona y una sal (KCl).

En la etapa preliminar, se sintetizaron algunas membranas para determinar los posibles niveles de concentración que se utilizarían experimentalmente en las membranas. Los niveles de los polímeros fueron: $(+)=17$ y $(-)=12$. Posteriormente las membranas fueron preparadas.

Los resultados obtenidos fueron satisfactorios, sin embargo tratando de aumentar el flujo permeado, optamos por disminuir la hidrofobicidad de la solución polimérica, introduciendo en ésta un polímero más hidrofílico, el Polimetacrilato de Metilo-PMMA.

En este trabajo son presentadas las membranas fabricadas en la etapa final. Como los resultados estuvieron dentro de las expectativas, fueron fabricadas las membranas elaboradas en la última etapa del estudio experimental. La Tabla 3 muestra estos niveles y los respectivos factores (reactivos).

Tabla 3: Composición polimérica de las membranas fabricadas ( $A=P V D F, B=$ Polisulfona, $\mathrm{C}=\mathrm{PMMA}$ )

\begin{tabular}{|l|l|l|l|}
\hline $\begin{array}{c}\text { Mem- } \\
\text { brana }\end{array}$ & \multicolumn{1}{|c|}{$\begin{array}{c}\text { Tipo } \\
\text { Polímero }\end{array}$} & $\begin{array}{c}\text { Conc. } \\
\text { Polímero }\end{array}$ & $\begin{array}{c}\text { Conc. } \\
\text { Sal }\end{array}$ \\
\hline 01 & $\mathrm{~A}+\mathrm{C}$ & $12+0,12$ & $3 \%$ \\
\hline 02 & $\mathrm{~B}+\mathrm{C}$ & $12+0,12$ & $3 \%$ \\
\hline 03 & $\mathrm{~A}+\mathrm{C}$ & $13,6+0,13$ & $3 \%$ \\
\hline 04 & $\mathrm{~B}+\mathrm{C}$ & $13,6+0,13$ & $3 \%$ \\
\hline 05 & $\mathrm{~A}+\mathrm{C}$ & $15,2+0,12$ & $3 \%$ \\
\hline 06 & $\mathrm{~B}+\mathrm{C}$ & $15,2+0,12$ & $3 \%$ \\
\hline 07 & $\mathrm{~A}+\mathrm{C}$ & $17+0,17$ & $3 \%$ \\
\hline 08 & $\mathrm{~B}+\mathrm{C}$ & $17+0,17$ & $3 \%$ \\
\hline
\end{tabular}

Todas las composiciones poliméricas fueron acrecentadas de $0,1 \%$ de PMMA con relación a la cantidad total del polímero principal.

Las membranas preparadas fueron evaluadas con relación a su capacidad para la eliminación de la bacteria $E$ coli y su capacidad para mantener un bueno flujo permeado.

La Figura 2 muestra la capacidad de las membranas fabricadas de reducir las bacteria $E$ coli y la Figura 3 , el flujo de permeado a través de las mismas. Se puede observar que todas las membranas lograron una ópti- ma remoción bacteriana, siendo que las membranas de 3 a 8 consiguieron eliminar completamente esta bacteria.

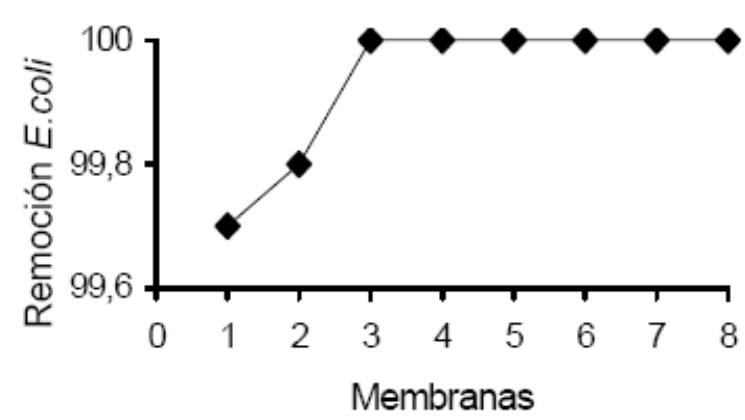

Fig. 2: Remoción de la Bacteria $E$ coli por las membranas fabricadas(M01, M02, M03, M04, M05, M06,M07,M08)

Esta eliminación tornó potable el agua con relación al parámetro bacteriológico. Las membranas 1 y 2 también, prácticamente, eliminaron la bacteria, con 99,7 y $99,8 \%$ de remoción respectivamente.

El flujo del agua contaminada, medido por 150 minutos, a través de las membranas se muestra en la Figura 2, donde se puede observar que no hubo una grande diferencia entre los flujos de las membranas M1A, M3A, M5A, M7A, M6B y M8B.

La membrana M4, sin embargo, presenta un flujo inicial más elevado, y un menor flujo estabilizado. Puede observarse así que el resultado más eficiente fue el obtenido en las membranas M6, M2 y M8, todas ellas, hechas a base de polisulfona.

Analizando los dos resultados conjuntamente, el flujo permeado y la remoción bacteriana, la mejor membrana fue la M4 $\left(300 \mathrm{~L} / \mathrm{hm}^{2}\right.$ y $100 \%$ de remoción). La Figura 4 muestra los radios promedios de las membranas preparadas. Puede observarse que los radios medios de las membranas preparadas están en un intervalo de ultra filtración, próximas de micro filtración $(0,1-0,001 \mu \mathrm{m})$.

La Figura 5 muestra la porosidad de la membrana M4 (que presentó los mejores resultados), a través de microscopia electrónica. Todas las membranas consiguieron eliminar el color y la turbiedad del agua. El pH se mantuvo prácticamente el mismo, sin alteraciones en su valor. 


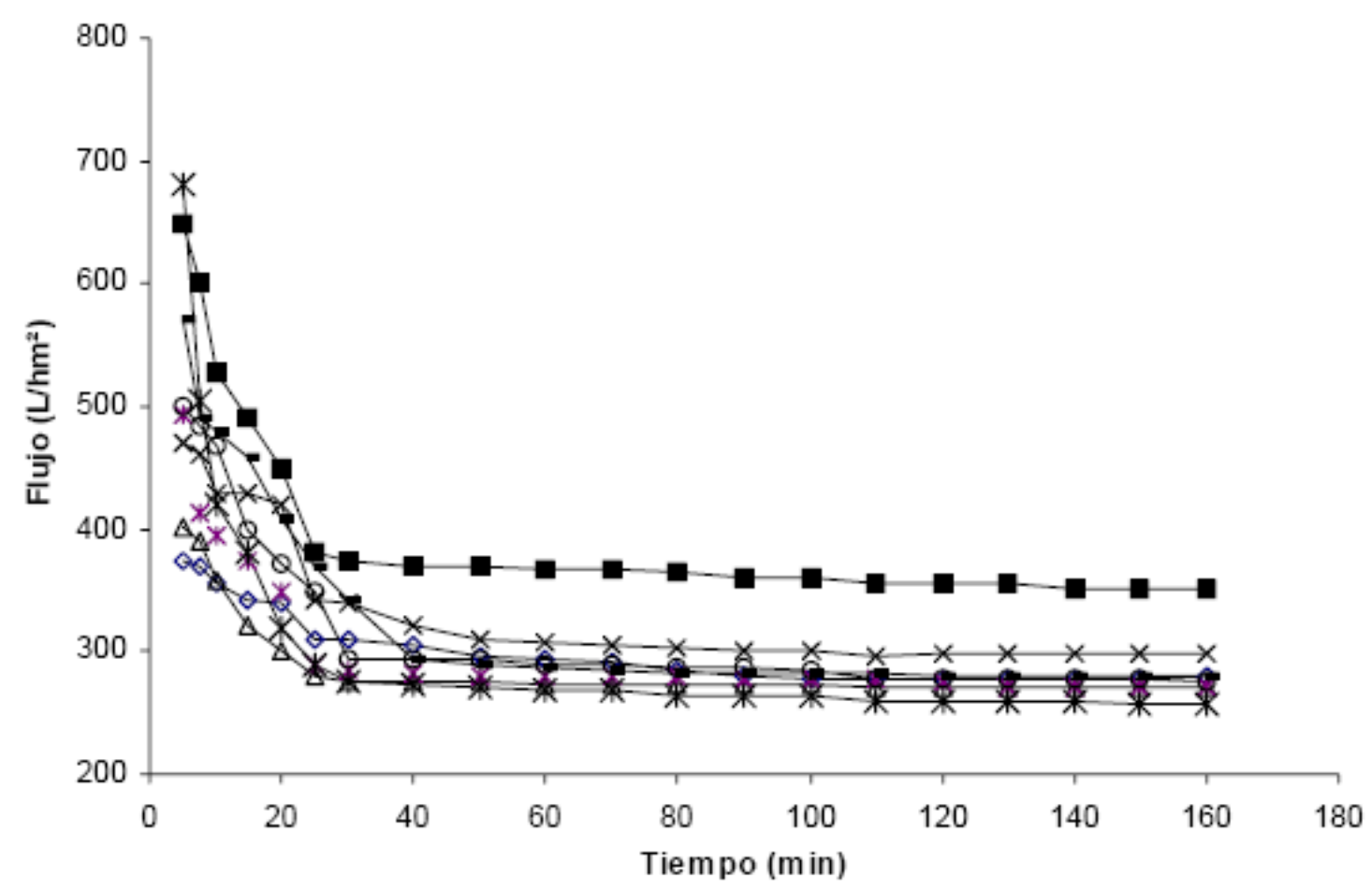

Fig. 3 : Flujo permeado por las membranas preparadas. Las curvas corresponden a: $\diamond \mathrm{M} 01$, — M02, $\Delta \mathrm{M} 03, \mathrm{x}$ M04, * M05, o M06, * M07, — M08

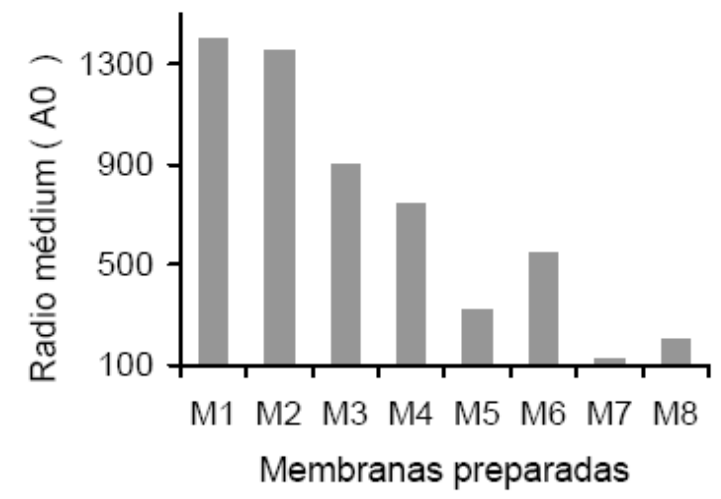

Fig. 4: Radios promedios de las membranas preparadas (M01, M02, M03, M04, M05, M06, M07, M08)

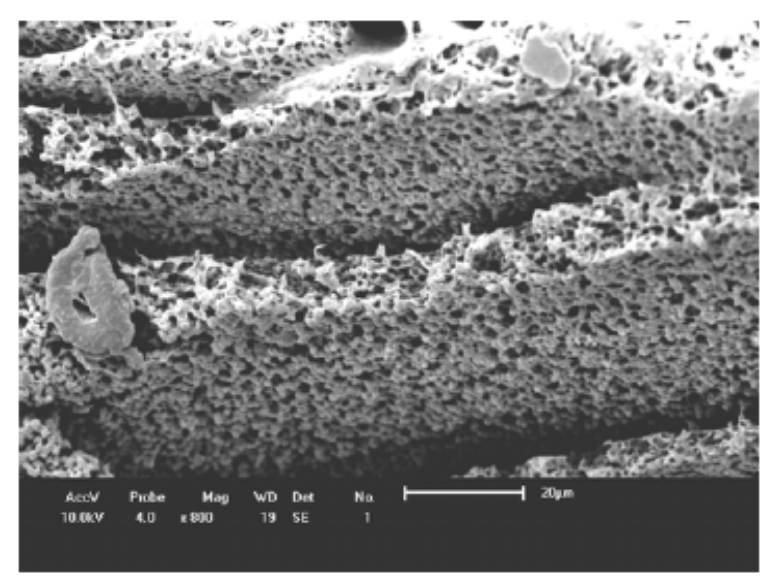

Fig. 5: Porosidad de la membrana M4

\section{CONCLUSIONES}

Este trabajo presenta un camino de obtención de buenas aguas usando membranas poliméricas asimétricas. Entre la variedad de tipos de membranas se optó por usar membranas de bajo costo, o sea, las producidas por los polímeros Polisulfona y PVDF.

En el estudio realizado, las membranas que presentaron el mejor resultado con respecto a la eliminación de la bacteria $E$ coli y con un flujo filtrado satisfactorio, fueron aquellas preparadas a partir de polisulfona.

Estos resultados muestran que usando membranas de este tipo es posible reducir significativamente elevadas cargas bacterianas, como Madaeni (1995), que demostró eliminación de virus y de E.coli a través de membrana de ultrafiltración.

De esta forma, se demuestra la posibilidad del uso de estas membranas como un factor de perfeccionamiento en el tratamiento de aguas contaminadas, que abre una nueva alternativa al uso del cloruro

Información Tecnológica - Vol. 18 No 1 - 2007 


\section{REFERENCIAS}

ABES Paraná, Informativo da Associação Brasileira de Engenharia Sanitária e Ambiental, Seção Paraná, n. 28 (setiembre de 2000).

APHA American Public Health Association, Standard Methods for the Examination for Water and Wastewater), $14^{\mathrm{a}}$ ed., Washington, USA (1995).

Madaeni, S.S., A. G. Fane, G. S. Grohmann, 1995, Virus removal from water and wastewater using membranes, Journal of Membrane Science v. 102,. 65-75 (1995).

Nóbrega, A.C, C. Borges, y A. Habert, Processo de Separação com Membranas, Rio de Janeiro: COPPE, 172 p., Apostila (Processos de Separação com Membranas) - Escola Piloto em Engenharia Química, UFRJ, Rio de Janeiro (1997).
Milles, A. A., S. S. Misra Estimation of the bactericide power of the bloods Journal Hygien n. 38 pp. $732-749$ (1938).

Petrus, J.C.C., Preparação, Modificação e Caracterização de Membranas Assimétricas para clarificação de suco de frutas, Campinas, Unicamp, 139 p.Tese Doutorado -FEAUniversidade Estadual de Campinas (1997).

Ribeiro, R.M. Preparo e utilização de membranas poliméricas assimétricas para produção de águas potáveis Maringá: UEM, 136 p.. Tese de Doutorado PEQ - Universidade Estadual de Maringa (2005).

Schneider, R.P. y M. T. Tsutiya, Membranas filtrantes para o tratamento de água,e Esgoto e Água de reúso, ABES, Associação Brasileira de Engenharia Sanitária e Ambiental, Capítulo Nacional da AIDIS, São Paulo, 234 (2001) 


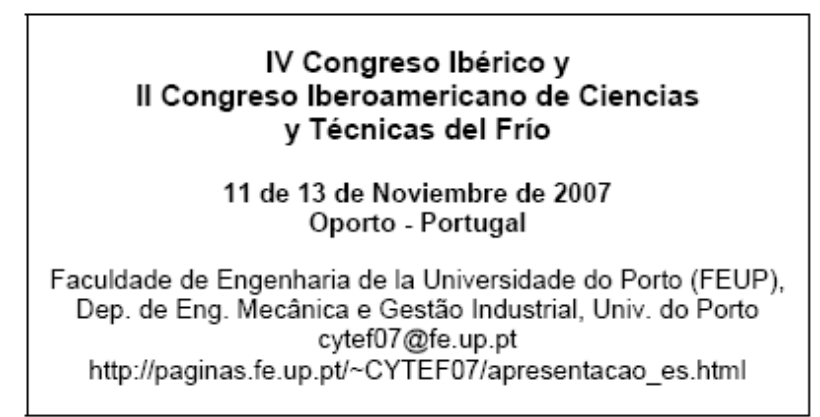

Tercer Congreso y Exposición Nacional de la
Industria del Acero
Noviembre de 2007
Monterrey - N.L - México
Asociación para la Tecnología del Hierro y del Acero
AIST México
aistmexico@axtel.net
http://www.aistmexico.org.mx/conac/call.asp

\begin{tabular}{|c|}
\hline VI Congreso Mundial de La Palta \\
12 al 16 Noviembre de 2007 \\
Viña del Mar - Chile \\
Informaciones: \\
Secretaría Congreso \\
e-mail: sec.congresos@tajamar.cl \\
http://www.congresomundialdelapalta.cl/index.html
\end{tabular}

\section{Abril 2008}

\section{Simposio Internacional sobre Sistemas Multicuerpo y Mecatrónica, MuSME 2008 \\ 8 al 12 de Abril de 2008 \\ San Juan - Argentina

$$
\text { Informaciones: }
$$ \\ Osvaldo Penisi (MuSMe 2008 Congress) \\ IMA, Inst. Mecánica Aplicada, Univ. Nac. de San Juan e-mail: musme2008@unsj.edu.a www.musme2008.unsj.edu.ar}

Junio 2008

\section{$8^{\circ}$ Congreso Mundial sobre Mecánica} Computacional (WCCM8)

\section{y}

$5^{\circ}$ Congreso Europeo sobre Métodos Computacionales en Ciencias Aplicadas e Ingeniería (ECCOMAS 2008)

30 de Junio al 5 de Julio de 2008 Venecia - Italia

Venice Convention Center iacm-eccomas08@cimne.upc.edu http://www.iacm-eccomascongress2008.org/frontal/ $19^{\circ}$ Congreso Mundial sobre Petróleo, WPC 2008

$$
29 \text { de Junio - } 03 \text { de Julio de } 2008
$$$$
\text { Madrid - España }
$$

Centro de Exposiciones y Congresos Juan Carlos I - IFEMA $\frac{\text { pcano@ethingsonline.com }}{\text { http: } / / \text { www.19wpc.com }}$

\section{Septiembre 2008}

$59^{\mathrm{a}}$ Congreso Anual del la Sociedad Internacional de Electroquímica

7 al 12 de Septiembre de 2008 Sevilla - España

Informaciones:

info@ise-online.org

http://www.ise-online.org/annmeet/next_meetings.php

\section{$2^{\circ}$ Congreso Europeo de Química}

16 al 20 de Septiembre de 2008 Torino - Italia

Evelyn McEwan, EuCheMS General Secretary Royal Soc. of Chemistry, Burlington House, Piccadilly, London W1J OBA, U.K.

e-mail:mcewane@rsc.org web site:http://www.euchems.org

\section{$2^{\text {a }}$ Conferencia Europea sobre Mecanismos en} Ciencia, EUCOMES 2008

17 al 20 de Septiembre de 2008

$$
\text { Cassino - Italia }
$$

Marco Ceccarelli (EUCOMES 2008)

Lab. of Robótica y Mecatrónica, Univ. de Cassino eucomes2008@unicas.it

www.webuser.unicas.it/weblarm/eucomes2008/

\section{Octubre 2008}

$12^{\circ}$ Congreso Internacional de la Sociedad sobre Protección a la Radiación

\section{9 al 24 de Octubre de 2008} Buenos Aires - Argentina

Informaciones:

secretariat@irpa12.org.ar

http://www.irpa12.org.ar/index.htm

V Congreso Iberoamericano de Física y Química Ambiental

Argentina en 2008

Informaciones:

gallard@usal.es miblesa@cnea.gov.ar http://www.sifyqa.org.es/estatutos.php 